\title{
Characteristics of Children 2 to 5 Years of Age With Severe Obesity
}

\author{
June M. Tester, MD, MPH, ${ }^{a}$ Thao-Ly T. Phan, MD, MPH, ${ }^{b}$ Jared M. Tucker, PhD, ${ }^{c}$ Cindy W. Leung, ScD, MPH, ${ }^{d}$ \\ Meredith L. Dreyer Gillette, PhD, ${ }^{e}$ Brooke R. Sweeney, MD, ${ }^{e}$ Shelley Kirk, PhD, RD, LD, ${ }^{f}$ \\ Alexis Tindall, RD, LD, s Susan E. Olivo-Marston, $\mathrm{PhD}, \mathrm{MPH},{ }^{\mathrm{h}}$ Ihuoma U. Eneli, MD, MSs
}

BACKGROUND AND OBJECTIVES: As a distinct group, 2- to 5-year-olds with severe obesity (SO) have not been extensively described. As a part of the Expert Exchange Workgroup on Childhood Obesity, nationally-representative data were examined to better characterize children with So.

METHODS: Children ages 2 to $5(N=7028)$ from NHANES (1999-2014) were classified as having normal weight, overweight, obesity, or SO (BMI $\geq 120 \%$ of 95 th percentile). Sociodemographics, birth characteristics, screen time, total energy, and Healthy Eating Index 2010 scores were evaluated. Multinomial logistic and linear regressions were conducted, with normal weight as the referent.

RESULTS: The prevalence of SO was $2.1 \%$. Children with SO had higher (unadjusted) odds of being a racial and/or ethnic minority (African American: odds ratio [OR]: 1.7; Hispanic: OR: 2.3). They were from households with lower educational attainment (OR: 2.4), that were single-parent headed (OR: 2.0), and that were in poverty (OR: 2.1). Having never been breastfed was associated with increased odds of obesity (OR: 1.5) and higher odds of SO (OR: 1.9). Odds of $>4$ hours of screen time were 1.5 and 2.0 for children with obesity and SO. Energy intake and Healthy Eating Index 2010 scores were not significantly different in children with SO.

CONGLUSIONS: Children ages 2 to 5 with SO appear to be more likely to be of a racial and/or ethnic minority and have greater disparities in social determinants of health than their peers and are more than twice as likely to engage in double the recommended screen time limit.

\begin{abstract}
aUniversity of California, San Francisco Benioff Children's Hospital Oakland, Oakland, California; ${ }^{\circ}$ Department of Pediatrics, Nemours Alfred I. DuPont Hospital for Children, Wilmington, Delaware; 'CHealthy Weight Center, Helen DeVos Children's Hospital, Grand Rapids, Michigan; 'Department of Nutritional Sciences, School of Public Health, University of Michigan, Ann Arbor, Michigan; ' Department of Pediatrics, Children's Mercy Kansas City and School of Medicine, University of Missouri-Kansas City, Kansas City, Missouri; 'fCincinnati Children's Hospital Medical Center, Cincinnati, Ohio; ${ }^{g}$ Nationwide Children's Hospital Center for Healthy Weight and Nutrition, Columbus, Ohio; and ${ }^{h}$ Division of Epidemiology, College of Public Health, The Ohio State University, Columbus, Ohio
\end{abstract}

Dr Tester conceptualized and designed the study, conducted the majority of the data analysis, drafted the initial manuscript, and reviewed and revised the manuscript; Dr Leung conducted key data analyses required for calculation of Healthy Eating Index 2010 diet data, contributed expertise to the data analysis approach, and reviewed and revised the manuscript; Drs Phan, Tucker, Dreyer Gillette, Sweeney, and Kirk and Ms Tindall contributed topical expertise in pediatric obesity for preparation of the manuscript, assisted with analysis interpretation, and reviewed and revised the manuscript; Dr Olivo-Marston contributed to early data analysis for the study and reviewed and revised the final manuscript; Dr Eneli contributed to initial conceptualization of
WHAT'S KNOWN ON THIS SUBJECT: Preschool-aged children with severe obesity are a group with high risk of future comorbidity; however, they are poorly characterized as a distinct group.

WHAT THIS STUDY ADDS: In this study using nationally representative data, preschool-aged children with severe obesity were found to have greater disparities in social determinants of health and a particularly high level of screen time use compared with their peers.
To cite: Tester JM, Phan T-L-T-, Tucker JM, et al. Char acteristics of Children 2 to 5 Years of Age With Severe Obesity. Pediatrics. 2018;141(3):e20173228 
After decades of prevention and treatment programs to address the concern over the epidemic of obesity in children, national data reveal an increase in prevalence rates among children at all ages. ${ }^{1}$ In 2016, the prevalence of obesity among children 2 to 19 years of age in the NHANES was $18.5 \% .^{1}$ This increasing trend has been particularly observed among those with more severe forms of obesity. ${ }^{2}$ Among 2- to 5-year-old children, $2.6 \%$ are estimated to have severe obesity (SO). ${ }^{2}$ These young children are at increased risk of later obesity and significant morbidity, including cardiopulmonary disease and behavioral and developmental concerns. Elevated inflammatory biomarkers, antecedents of cardiovascular and metabolic disease, have been significantly associated with obesity as early as age $3 .^{3}$

In response to the need for treatment options for the complex, high-acuity population of chidlren with severe obesity, the American Academy of Pediatrics Institue for Healthy Childhood Weight and the Children's Hospital Association convened the Expert Exchange Workgroup on Childhood Obesity, which was an interdisciplinary team comprised of obesity programs across the United States. Although there have been investigations in the prevalence of SO in young children, few study authors have described this population or how children with SO compare with their peers who have overweight (OW) or obesity in regards to social determinants of health, diet, and activity patterns. It was identified as a priority to better characterize this growing population of children as an initial step to understanding their medical and psychosocial needs as we develop targeted and effective interventions.

The purpose of this study was to evaluate sociodemographic and lifestyle characteristics of children 2 to 5 years old with SO in comparison with their counterparts with normal weight (NW), OW, and obesity in NHANES from 1999 to 2014.

\section{METHODS}

\section{Study Population}

We examined participants from NHANES, which is a complex, multistage probability crosssectional sample designed to be representative of the US civilian, noninstitutionalized population. This analysis combined data from 7 2-year cycles of data from 1999 to 2014 . We included children 2 to 5 years $(\geq 24$ but $<72$ months of age) at the time of their examination in the mobile examination center (MEC). A total of 7028 children had complete weight and height data and composed the study sample.

\section{Measures}

\section{Anthropometrics}

Height and weight were measured by trained personnel at the MEC by using standardized protocols. ${ }^{4}$ Ageand sex-specific BMI percentiles were calculated by using SAS (SAS Institute, Inc, Cary, NC) code provided by the Centers for Disease Control and Prevention. ${ }^{5}$ Children 2 to 5 years old were classified into the following mutually-exclusive weight categories: (1) NW (BMI $<85$ th percentile); (2) OW (BMI 85th to $<95$ th percentile); (3) obesity (BMI $\geq 95$ th percentile to $<120 \%$ (1.2 times) the 95th percentile); and (4) SO (BMI $\geq 120 \%$ of the 95 th percentile). The recommended definition of SO is having a "BMI $\geq 120 \%$ of the 95 th percentile or a BMI of 35, whichever is lower." $2,6,7$ No children in this sample had a BMI > 35. Technically, children with SO who are at or above $140 \%$ of the 95th percentile can furthermore be classified into a higher-tier risk category (Class III obesity). ${ }^{2}$ However, because of a particularly small sample size $(N=32)$, children with Class III obesity were not analyzed as a distinct group. Children under the age of 2 years are assessed with weight for length rather than BMI. As such, they are not able to be classified by using BMI criteria for SO and were not included in the analysis.

\section{Demographic and Birth Characteristics}

The caregiver from the household who was the most knowledgeable about the child, most often a parent, completed the questionnaires. Information obtained included the child's race and ethnicity, age, sex, household income, and partnered status (married or partnered, single, divorced, or widowed) as well as educational attainment (any college, high school or less) of the household respondent. Maternal age and birth weight were reported, and we analyzed maternal age as a continuous variable and grouped birth weight into 3 categories: low ( $<2500$ g), normal (2500-<4000 g), and high ( $\geq 4000$ g). Maternal smoking "at any time" during pregnancy and a history of whether the child was "ever breastfed or fed breast milk" were assessed. Annual household income and family size are used with each cycle of NHANES to calculate the index of family income to the federal poverty level (FPL). ${ }^{8}$ Household income $\geq 300 \%$ of the FPL was categorized as the "higher income" referent and was compared with being $200 \%$ to $299 \%, 100 \%$ to $199 \%$, and $<100 \%$ of FPL.

\section{Physical Activity and Screen Time}

From 2001 to 2014, television viewing and time spent using computer and/or video games was evaluated by asking about average hours per day "over the past 30 days." For 1999-2000, these respective questions referred to "yesterday," rather than to the daily average over the past 30 days, but were otherwise analogous and were combined with responses from future years to maximize sample size, in a method consistent with that of previous studies. ${ }^{9}$ Response options were identical across all years 
(1999-2014) and included "none," "<1 hour," "1 hour," "2 hours," "3 hours," "4 hours," and "5 hours or more." Less than 1 hour was coded as 0.5 hours and 5 hours or more was coded as 5 hours. Television viewing was dichotomized: ( $\leq 2$ vs $>2$ hours) and ( $\leq 3$ vs $>3$ hours). Reported television time was summed with computer and/or video game time to create a variable representing total daily screen time and was dichotomized as $\leq 2 \mathrm{vs}>2$ hours to correspond with current recommendations, $\leq 3$ vs $>3$ hours, and $\leq 4$ vs $>4$ hours to assess use that doubled the guidelines. ${ }^{10,11}$ To ensure question compatibility across years, mean screen time from NHANES cycles with altered wording (19992000 and 2011-2014) was compared with overall estimates, revealing no significant differences (data not shown).

Physical activity was indexed differently in 1999-2008 than in 2009-2014, and therefore the data could not be combined in the analysis; thus, physical activity data were excluded from the current analyses.

\section{Dietary Recall Data}

From 1999 to 2014, one 24-hour dietary recall was conducted in person at the MEC with the person most knowledgeable about the child's dietary intake. Overall dietary quality was assessed by using the Healthy Eating Index 2010 (HEI-2010). Developed by the US Department of Agriculture Center for Nutrition Policy and Promotion, the HEI-2010 measures conformance with the 2010 Dietary Guidelines for Americans. ${ }^{12}$ The HEI-2010 score is the sum of 12 component scores (total fruit, whole fruit, total vegetables, greens and beans, whole grains, dairy, total protein foods, seafood and plant proteins, fatty acids, refined grains, sodium, and empty calories), with a maximum score of 100 points. For reference, in 2007-2008, the average score for all US children combined was 49.8. ${ }^{13}$ The Food Patterns Equivalents Database, ${ }^{14}$ which converts foods and beverages reported in NHANES to US Department of Agriculture food pattern components, was used to estimate component scores for the HEI-2010. Of the children in the analytic sample, 6236 (89\%) had a sufficiently reliable and complete dietary recall for calculating HEI2010 scores.

\section{Statistical Analyses}

Survey weights were used to account for the complex, multistage probability sampling design used in NHANES, in accordance with recommendations from the National Center for Health Statistics. ${ }^{8}$ Examination weights were used to create 16-year weights for all analyses except the diet data, for which the diet recall weighting was used. Weighted means with SEs were estimated with Taylor series linearization to describe the continuous variables. Linear regression coefficients and 95\% confidence intervals (CIs) are presented from unadjusted linear regression between continuous variables and weight category. Dietary data were adjusted for the child's age and sex, and the 12 HEI-2010 components were each examined as log-transformed outcomes because of skewed distributions.

For categorical variables, multinomial logistic regression was conducted with the 4 weight categories, using NW as the reference category. Odds ratios (ORs) for sociodemographic and birth characteristic variables are presented in unadjusted models. Screen time and diet were adjusted for child's age and sex.

All analyses were conducted by using Stata 12.1 (StataCorp, College Station, TX).

\section{RESULTS}

\section{Demographics}

Of the total sample ( $N=7028), 5291$ (76.5\%) were classified as having NW, 918 (13.0\%) were classified as having OW, 662 (8.4\%) were classified as having obesity, and 157 $(2.1 \%)$ were classified as having SO.

The mean age was higher among children with obesity (49.6 months) and SO (56.5 months) than among children with NW (47.3 months) (Table 1). In a multinomial logistic regression, the odds of obesity and SO for Non-Hispanic African American children were 1.5 (95\% CI: 1.2 to 1.9 ) and 1.7 (95\% CI: 1.0 to 3.0), respectively, compared with Non-Hispanic white children. For Hispanic children, the odds of obesity and SO were 2.0 (95\% CI: 1.6 to 2.6 ) and 2.3 (95\% CI: 1.4 to 3.7 ), respectively. Sex was not a significant predictor for severity of obesity.

Mean household income was $228 \%$ of the FPL (SE: 4.8 ), and incomes at the 25th and 75th percentiles corresponded to $91 \%$ and $361 \%$ of the FPL, respectively. In an unadjusted model, children of households with incomes below the FPL had odds of OW, obesity, and SO of 1.3 (95\% CI: 1.0 to 1.7), 1.6 (95\% CI: 1.2 to 2.2 ), and 2.1 (95\% CI: 1.1 to 4.0), respectively, compared with children in households at or above $300 \%$ of the FPL.

Lower educational attainment of the household respondent (high school degree or less compared with having had some college attendance) was associated with significantly greater odds of a child having OW (OR: $1.5,95 \%$ CI: 1.2 to 1.8 ), obesity (OR: $1.5,95 \%$ CI: 1.2 to 1.9 ), or SO (OR: $2.4,95 \%$ CI: 1.5 to 3.9). Children from a single caregiver household had elevated odds of obesity (OR: 1.4, 95\% CI: 1.1 to 1.7 ) and twice the odds of SO (OR: 2.0, 95\% CI: 1.3 to 3.0 ). 
TABLE 1 Demographics of Sample $(N=7028)$ : Distribution of Demographic Characteristics and Bivariate Associations With Weight Status in Children Aged 2 to 5 Years, NHANES 1999-2014

\begin{tabular}{|c|c|c|c|c|c|c|c|c|c|}
\hline & \multirow[t]{2}{*}{$\begin{array}{l}\text { Mean }^{a} \\
\text { (SE) }\end{array}$} & \multicolumn{2}{|c|}{$\begin{array}{l}\text { NW (<85th Percentile), } \\
\quad n=5291 \text { (76.5\%) }\end{array}$} & \multicolumn{2}{|c|}{$\begin{array}{l}\text { OW (85th Percentile-94.9th } \\
\text { Percentile), } n=918 \text { (13.0\%) }\end{array}$} & \multicolumn{2}{|c|}{$\begin{array}{c}\text { Obesity }(\geq 95 \text { th } \\
\text { Percentile-1.2 } 2 \times 95 \text { th } \\
\text { Percentile), } n=662(8.4 \%)\end{array}$} & \multicolumn{2}{|c|}{$\begin{array}{c}\text { SO }(\geq 1.2 \times 95 \text { th Percentile }) \\
n=157(2.1 \%)\end{array}$} \\
\hline & & Mean (SE) & $\begin{array}{l}\text { Coefficient }{ }^{b} \\
(95 \% \mathrm{Cl})\end{array}$ & Mean (SE) & Coefficient $(95 \% \mathrm{Cl})$ & $\begin{array}{c}\text { Mean } \\
\text { (SE) }\end{array}$ & $\begin{array}{l}\text { Coefficient }(95 \% \\
\text { CI) }\end{array}$ & $\begin{array}{l}\text { Mean } \\
\text { (SE) }\end{array}$ & $\begin{array}{l}\text { Coefficient }(95 \% \\
\text { CI) }\end{array}$ \\
\hline \multicolumn{10}{|l|}{ Age } \\
\hline Child (mo) & $47.7(0.2)$ & $47.3(0.2)^{\mathrm{c}}$ & Ref & $47.5(0.6)$ & $0.16(-1.0$ to 1.3$)$ & $49.6(0.7)$ & $2.2^{*}(0.7$ to 3.8$)$ & $56.5(1.3)$ & $9.2^{*}(6.6$ to 11$)$ \\
\hline Mother (y) & $\begin{array}{c}27.5(0.1) \\
n(\%)^{\mathrm{a}}\end{array}$ & $\begin{array}{c}27.6(0.1) \\
n(\%)\end{array}$ & $\begin{array}{c}\text { Ref } \\
\text { OR }(95 \% \mathrm{CI})^{\mathrm{C}}\end{array}$ & $\begin{array}{c}27.3(0.3) \\
n(\%)\end{array}$ & $\begin{array}{c}-0.3(-0.9 \text { to } 0.2) \\
\text { OR }(95 \% \mathrm{Cl})\end{array}$ & $\begin{array}{c}27.0(0.3) \\
n(\%)\end{array}$ & $\begin{array}{c}-0.6^{*}(-1.3 \text { to } 0.0) \\
\text { OR }(95 \% \mathrm{CI})\end{array}$ & $\begin{array}{c}26.6(0.6) \\
n(\%)\end{array}$ & $\begin{array}{c}-1.0(-2.6 \text { to } 0.3) \\
\text { OR (95\% CI) }\end{array}$ \\
\hline \multicolumn{10}{|l|}{ Sex (child) } \\
\hline Female & $3456(49.6)$ & $2637(50.2)$ & Ref & $426(46.8)$ & Ref & $327(47.8)$ & Ref & $66(48.1)$ & Ref \\
\hline Male & $3572(50.4)$ & $2654(49.8)$ & Ref & $492(53.2)$ & $1.1(0.9$ to 1.4$)$ & $335(52.2)$ & $1.1(0.9$ to 1.3$)$ & $91(51.9)$ & $1.1(0.7$ to 1.6$)$ \\
\hline \multicolumn{10}{|c|}{ Race and/or ethnicity (child) } \\
\hline $\begin{array}{l}\text { Non-Hispanic } \\
\text { white }\end{array}$ & $2045(54.6)$ & $1604(56.3)$ & Ref & $264(54.2)$ & Ref & $146(43.6)$ & Ref & $31(42.3)$ & Ref \\
\hline Hispanic & $2522(23.0)$ & $1782(21.0)$ & Ref & $361(25.8)$ & $1.3^{*}(1.0$ to 1.6$)$ & $304(33.1)$ & $2.0^{*}$ (1.6 to 2.6$)$ & $75(36.1)$ & $2.3^{*}(1.4$ to 3.7$)$ \\
\hline $\begin{array}{l}\text { Non-Hispanic } \\
\quad \text { African } \\
\text { American }\end{array}$ & $1843(14.4)$ & $1401(14.2)$ & Ref & $224(13.4)$ & $1.0(0.8$ to 1.2$)$ & $174(16.4)$ & $1.5^{\star}(1.2$ to 1.9$)$ & $44(18.5)$ & $1.7^{*}(1.0$ to 3.0$)$ \\
\hline $\begin{array}{l}\text { Other or } \\
\text { mixed }\end{array}$ & $618(8.0)$ & $504(8.5)$ & Ref & $69(6.6)$ & 0.8 (0.6 to 1.2$)$ & $38(6.9)$ & $1.0(0.7$ to 1.7$)$ & $7(3.1)$ & 0.5 (0.2 to 1.2$)$ \\
\hline \multicolumn{10}{|c|}{ Household income, \% FPL } \\
\hline$\geq 300$ & $1360(31.8)$ & $1109(33.6)$ & Ref & $145(27.3)$ & Ref & $90(24.9)$ & Ref & $16(20.0)$ & Ref \\
\hline $200-299$ & $819(14.8)$ & $623(14.8)$ & Ref & $104(15.0)$ & $1.2(0.9$ to 1.7$)$ & $76(14.6)$ & $1.3^{*}(1.2$ to 2.2$)$ & $16(14.6)$ & $1.7(0.6$ to 4.1$)$ \\
\hline $100-199$ & $1810(25.6)$ & $1330(24.6)$ & Ref & $252(28.6)$ & $1.4^{*}(1.1$ to 1.9$)$ & $181(28.3)$ & $1.5^{\star}$ (1.0 to 2.2$)$ & 47 (31.8) & $2.2^{*}(1.0$ to 4.4$)$ \\
\hline$<100$ & $2521(27.8)$ & $1850(27.0)$ & Ref & $340(29.1)$ & $1.3^{*}(1.0$ to 1.7$)$ & $267(32.2)$ & $1.6^{*}(1.2$ to 2.2$)$ & $64(33.6)$ & $2.1^{*}(1.1$ to 4.0$)$ \\
\hline \multicolumn{10}{|c|}{ Education (respondent) } \\
\hline Any college & 3014 (54.9) & $2383(57.5)$ & Ref & $349(48.1)$ & Ref & $239(47.0)$ & Ref & $43(35.8)$ & Ref \\
\hline $\begin{array}{l}\text { Less than HS } \\
\text { or GED }\end{array}$ & $3778(45.1)$ & $2735(42.5)$ & Ref & $544(51.9)$ & $1.5^{\star}(1.2$ to 1.8$)$ & $392(53.0)$ & $1.5^{*}(1.2$ to 1.9$)$ & $107(64.2)$ & $2.4^{*}$ (1.5 to 3.9$)$ \\
\hline \multicolumn{10}{|c|}{ Marital status (respondent) } \\
\hline Married & $4633(78.8)$ & $3533(79.7)$ & Ref & $594(77.8)$ & Ref & $421(75.0)$ & Ref & $85(66.4)$ & Ref \\
\hline Single & $1932(21.2)$ & $1401(20.3)$ & Ref & $269(22.3)$ & $1.2(0.9$ to 1.4$)$ & $202(25.0)$ & $1.4^{\star}(1.1$ to 1.7$)$ & $60(33.7)$ & $2.0^{\star}(1.3$ to 3.0$)$ \\
\hline
\end{tabular}

GED, general education diploma; HS, high school; Ref, reference.

a All $N$ 's and $n$ 's listed are unweighted (raw), all means and proportions are survey-weighted.

${ }^{b}$ Coefficients from unadjusted linear regression.

${ }^{\mathrm{C}} \mathrm{ORs}$ from unadjusted multinomial logistic regression.

${ }^{*} P<.05$.

\section{Birth and Infancy Characteristics}

Mean maternal age was lower with each progressive weight category (Table 2). However, in simple linear regression, only the mean maternal age among mothers of children with obesity ( 27.0 years) was significantly lower than the mean age among mothers of children with NW (27.6 years). Maternal smoking was associated with increased odds of obesity (OR: 1.4, 95\% CI: 1.0 to 1.9) but not SO.

In this sample, the survey-weighted proportions of children born at a high birth weight (HBW) (>4000 g) were $12.1 \%, 16.3 \%$, and $9.1 \%$, respectively, for children with $\mathrm{OW}$, obesity, and SO, compared with 8.5\% of NW children. Compared with those with normal birth weight, having had an HBW was associated with a twofold increase in odds of obesity (OR: 2.0, 95\% CI: 1.5 to 2.8) but not SO. A history of low birth weight $(<2500 \mathrm{~g})$ was associated with lower odds of being OW (OR: $0.6,95 \% \mathrm{CI}$ : 0.4 to 0.9 ) but was not associated with obesity or SO. The proportion of children who had never been breastfed was increasingly higher in children with obesity (38.9\%) and SO (44\%) compared with NW children (29.3\%). Having never been breastfed was associated with increased odds of obesity (OR: 1.5, 95\% CI: 1.2 to 2.0 ) and higher odds of SO (OR: $1.9,95 \%$ CI [1.3 to 2.8]).

\section{Screen Time}

Roughly a quarter of children with NW and OW watched $>2$ hours per day of television. This proportion was higher for children with obesity (33.0\%) and even higher for children with SO (37.2\%). Compared with their peers with NW, the odds of watching $>2$ hours per day of television were 1.4 (95\% CI: 1.0 to 1.7) for children with obesity (and although the odds were higher, the degree was not significant for children with SO). Compared with 
TABLE 2 Birth and Infancy Characteristics: Bivariate Multinomial Logistic Regressions With Weight Status in Children Aged 2 to 5 Years, NHANES $1999-2014$

\begin{tabular}{|c|c|c|c|c|c|c|c|c|c|}
\hline & \multirow[t]{2}{*}{$n(\%)^{\mathrm{a}}$} & \multicolumn{2}{|c|}{$\begin{array}{l}\text { NW (<85th Percentile), } \\
\qquad n=3907\end{array}$} & \multicolumn{2}{|c|}{$\begin{array}{l}\text { OW (85th Percentile-94.9th } \\
\text { Percentile), } n=676\end{array}$} & \multicolumn{2}{|c|}{$\begin{array}{c}\text { Obesity }(\geq 95 \text { th } \\
\text { Percentile-1. } 2 \times 95 \text { th } \\
\text { Percentile), } n=510\end{array}$} & \multicolumn{2}{|c|}{$\begin{array}{c}\text { So ( } \geq 1.2 \times 95 \text { th Percentile }) \\
n=123\end{array}$} \\
\hline & & $n(\%)$ & OR $\mathrm{R}^{\mathrm{b}}(95 \% \mathrm{Cl})$ & $n(\%)$ & OR (95\% Cl) & $n(\%)$ & OR (95\% Cl) & $n(\%)$ & OR (95\% Cl) \\
\hline $\begin{array}{l}\text { Low birth wt }(<2500 \\
\text { g) }\end{array}$ & $678(8.5)$ & $561(9.3)$ & Ref & $57(5.2)$ & $0.6^{*}(0.4$ to 0.9$)$ & $45(5.8)$ & 0.7 (0.4 to 1.5$)$ & $15(12.2)$ & $1.0(0.5$ to 2.0$)$ \\
\hline $\begin{array}{l}\text { Normal birth wt } \\
\quad(2500-4000 \text { g) }\end{array}$ & 5598 (81.8) & $4219(82.2)$ & Ref & $746(82.6)$ & Ref & $511(77.9)$ & Ref & $122(78.6)$ & Ref \\
\hline HBW (>4000 g) & $591(9.7)$ & $391(8.5)$ & Ref & $98(12.2)$ & $1.2(0.9$ to 1.7$)$ & $100(16.3)$ & $2.0^{*}$ (1.5 to 2.8$)$ & $17(9.2)$ & $1.1(0.5$ to 2.4$)$ \\
\hline $\begin{array}{l}\text { Mother smoked } \\
\text { during pregnancy }\end{array}$ & $928(16.5)$ & $677(14.0)$ & Ref & $126(15.0)$ & 1.1 (0.8 to 1.4$)$ & $103(18.2)$ & $1.4^{\star}(1.0$ to 1.9$)$ & $22(20.8)$ & $1.6(0.9$ to 2.8$)$ \\
\hline Never breastfed & $2430(30.7)$ & 1777 (29.3) & Ref & 328 (31.3) & 1.1 (0.9 to 1.3$)$ & 255 (38.9) & $1.5^{*}(1.2$ to 2.0$)$ & $70(44.0)$ & $1.9^{*}(1.3$ to 2.8$)$ \\
\hline
\end{tabular}

Ref, reference.

a All N's and $n$ 's listed are unweighted (raw) and all proportions are survey-weighted.

b Unadjusted ORs from multinomial logistic regression.

${ }^{*} P<.05$.

their peers with NW, the odds of watching $>3$ hours per day of television were higher for children with obesity (OR: 1.6, 95\% CI: 1.2 to 2.1) and highest for those with SO (OR: $1.9,95 \%$ CI: 1.1 to 0.3 ).

Total screen time exceeded the recommended limit of 2 hours in more than half of the children in the sample; it was $>2$ hours per day for $57.3 \%, 59.9 \%, 66.8 \%$, and $66.5 \%$ of children with NW, OW, obesity, and SO, respectively. Compared with peers with NW, the odds of having a total screen time $>2$ hours per day were higher for children with obesity (OR: $1.4,95 \% \mathrm{CI}: 1.2$ to 1.8 ), although the trend was not statistically significant for children with SO (OR: 1.5, 95\% CI: 0.8 to 2.0). High levels of total screen time ( $>3$ and $>4$ hours per day) were consistently associated with higher odds of obesity that were greatest for children with SO. Compared with their peers with NW, the odds of having screen time $>4$ hours per day were higher for children with obesity (OR: 1.5 , 95\% CI: 1.2 to 1.9 ) and particularly elevated for children with SO (OR: 2.0, 95\% CI: 1.2 to 3.3 ).

\section{Diet}

Mean energy intake in daily kilocalories was $1575 \mathrm{kcal} /$ day (SE: 10) for the entire sample, with respective means by category as follows: NW: 1558 kcal/day (SE: 11), OW: 1619 kcal/day (SE: 29), obesity: $1644 \mathrm{kcal} /$ day (SE: 34), and SO: $1644 \mathrm{kcal} /$ day (SE: 59) (Tables 3 and 4). After adjusting for age and sex, the respective additional daily energy intakes among children with OW, obesity, and SO were not statistically significant.

The HEI-2010 score for the entire sample was 51.1 (SE: 0.4), and mean scores by weight status were 51.1 (SE: 0.4), 52.3 (SE: 0.7), 49.4 (SE: 0.8 ), and 49.7 (SE: 1.5) for children with NW, OW, obesity, and SO, respectively. In adjusted analyses, the HEI-2010 difference with peers with NW was not significant for children with OW, obesity, or SO $(0.2,95 \%$ CI: -2.9 to 3.3 ). The 12 HEI-2010 components were each examined in linear regression as log-transformed outcomes, and none of the 12 HEI-2010 component scores were significantly associated with SO.

\section{DISCUSSION}

Children with SO represent a growing subgroup of children with an increased risk for significant morbidity. As part of a broader effort of the American Academy of Pediatrics Institute for Healthy
Childhood Weight and the Children's Hospital Association Expert Exchange, this analysis was conducted to better characterize young children with SO and factors associated with the development of SO in early childhood by using a nationally representative data set. In the Early Childhood Longitudinal Study Birth Cohort, Flores and $\operatorname{Lin}^{15}$ found that greater odds of SO were associated with Hispanic race, preschool attendance, and food frequency questions such as number of sugary beverages per week. With our findings, we highlight multiple social determinants and excessive screen time, in particular, as key factors associated with increased odds of SO in this population.

These results reveal that, regardless of weight status, more than half of 2- to 5-year-olds in the United States surpass current guidelines to limit screen time to 2 hours per day. ${ }^{10,11}$ Among preschool-aged children with SO, screen time use is even more abundant, with more than two-thirds exceeding the recommended 2-hour limit and more than one-quarter reporting screen time use beyond 4 hours per day. The authors are unaware of previous studies in which associations between $\mathrm{SO}$ and screen time in this demographic are described; however, 
TABLE 3 Screen Time: Bivariate Analysis With Weight Status in Children Aged 2 to 5 Years, NHANES 1999-2014

\begin{tabular}{|c|c|c|c|c|c|c|c|c|c|}
\hline & \multirow{3}{*}{$\begin{array}{c}\text { Total } \\
\text { (All wt) } \\
n=6762 \\
n^{\text {a }(\%)}\end{array}$} & \multicolumn{2}{|c|}{ NW (<85th Percentile) } & \multicolumn{2}{|c|}{$\begin{array}{l}\text { OW (85th Percentile- } \\
\text { 94.9th Percentile) }\end{array}$} & \multicolumn{2}{|c|}{$\begin{array}{c}\text { Obesity }(\geq 95 \text { th } \\
\text { Percentile- } 1.2 \times 95 \text { th } \\
\text { Percentile })\end{array}$} & \multicolumn{2}{|c|}{ So $(\geq 1.2 \times 95$ th Percentile $)$} \\
\hline & & \multicolumn{2}{|c|}{$n=5084$} & \multicolumn{2}{|c|}{$n=882$} & \multicolumn{2}{|c|}{$n=643$} & \multicolumn{2}{|c|}{$n=153$} \\
\hline & & $n(\%)$ & $\begin{array}{c}0 \mathrm{R}^{\mathrm{b}} \\
(95 \% \mathrm{Cl})\end{array}$ & $n(\%)$ & OR (95\% Cl) & $n(\%)$ & OR (95\% Cl) & $n(\%)$ & OR (95\% Cl) \\
\hline \multicolumn{10}{|l|}{ Screen time } \\
\hline Television time $>2 \mathrm{~h}$ & 2085 (27.3) & $1533(26.5)$ & Ref & $266(26.7)$ & 1.0 (0.8 to 1.2 ) & $228(33.2)$ & $1.4^{*}(1.1$ to 1.7$)$ & $58(37.2)$ & 1.5 (1.0 to 2.4$)$ \\
\hline Television time $>3 \mathrm{~h}$ & $1091(13.4)$ & 777 (12.6) & Ref & $148(13.3)$ & $1.1(0.8$ to 1.4$)$ & $133(18.6)$ & $1.6^{*}(1.2$ to 2.1$)$ & $33(21.8)$ & $1.9^{\star}$ (1.1 to 3.3 ) \\
\hline Total screen time $>2 \mathrm{~h}$ & $4101(58.6)$ & $3037(57.3)$ & Ref & 542 (59.9) & $1.1(0.9$ to 1.3$)$ & $421(66.8)$ & $1.4^{*}(1.2$ to 1.8$)$ & $101(66.5)$ & 1.5 (0.8 to 2.0$)$ \\
\hline Total screen time $>3 \mathrm{~h}$ & $2277(30.0)$ & $1664(29.0)$ & Ref & $296(29.5)$ & 1.0 (0.8 to 1.2$)$ & $251(36.6)$ & $1.4^{*}(1.1$ to 1.8$)$ & $66(43.2)$ & $1.7^{*}(1.1$ to 2.7$)$ \\
\hline Total screen time $>4 \mathrm{~h}$ & $1262(15.8)$ & $900(14.7)$ & Ref & $170(17.1)$ & $1.2(0.9$ to 1.6$)$ & $154(21.1)$ & $1.5^{*}(1.2$ to 1.9$)$ & $38(27.1)$ & $2.0^{\star}$ (1.2 to 3.3 ) \\
\hline
\end{tabular}

Ref, reference.

a All N's and $n$ 's listed are unweighted (raw), and all proportions are survey-weighted.

${ }^{b}$ ORs from multinomial logistic regression, adjusting for age and sex of the child

${ }^{*} P<.05$.

TABLE 4 Diet Quality: Bivariate Analysis With Weight Status in Children Aged 2 to 5 Years, NHANES 1999-2014

\begin{tabular}{|c|c|c|c|c|c|c|c|c|c|}
\hline & Total & \multicolumn{2}{|r|}{ NW } & \multicolumn{2}{|c|}{ OW } & \multicolumn{2}{|r|}{ Obesity } & \multirow{2}{*}{\multicolumn{2}{|c|}{$\frac{\text { SO }}{n=139(2.1 \%)}$}} \\
\hline & $n=6236(100 \%)$ & \multicolumn{2}{|c|}{$n=4702(76.6 \%)$} & \multicolumn{2}{|r|}{$n=813(13.1 \%)$} & \multicolumn{2}{|r|}{$n=582(8.2 \%)$} & & \\
\hline & $\operatorname{Mean}^{a}(\mathrm{SE})$ & $\begin{array}{l}\text { Mean } \\
\text { (SE) }\end{array}$ & Coefficient (95\% Cl) & $\begin{array}{l}\text { Mean } \\
\text { (SE) }\end{array}$ & Coefficient (95\% Cl) & $\begin{array}{l}\text { Mean } \\
\text { (SE) }\end{array}$ & $\begin{array}{l}\text { Coefficient } \\
(95 \% \mathrm{Cl})\end{array}$ & $\begin{array}{l}\text { Mean } \\
(\mathrm{SE})\end{array}$ & Coefficient (95\% Cl) \\
\hline $\begin{array}{l}\text { Energy intake } \\
\text { (kcal per d) }\end{array}$ & $1575(10)$ & $1558(12)$ & Ref & $1619(33)$ & $57.0(-3.3$ to 117.3$)$ & $1644(37) €$ & $61.1(-11.9$ to 134.1$)$ & $1644(63)$ & $8.6(-101.5$ to 118.7$)$ \\
\hline $\begin{array}{l}\text { HEl-2010 score } \\
\text { (out of } 100 \\
\text { points) }\end{array}$ & $51.1(0.4)$ & $51.1(0.4)$ & Ref & $52.3(0.7)$ & $1.2(-0.2$ to 2.6$)$ & $49.4(0.8)$ & $-1.3(-2.9$ to 0.2$)$ & $49.7(1.5)$ & $0.2(-2.9$ to 3.3$)$ \\
\hline
\end{tabular}

Coefficients from linear regression adjusting for age and sex of the child. Ref, reference.

a Linearized means with SEs.

results are mixed when comparing previous NHANES literature in which associations of physical and sedentary activity with adiposity in children of a wider age range are described. Using the NHANES 20012004, Anderson et al $^{16}$ found that children 4 to 11 years with obesity had increased odds of elevated screen time and low physical activity. In the NHANES 1999-2006, Fulton et $\mathrm{al}^{9}$ did not find increased odds of OW or obesity (BMI $>85$ th percentile) among 2- to 5-year-olds with elevated screen time but did find increased odds among 6- to 15-year-old girls and 12- to 15-yearold boys. Our data reveal a strong dose-response relationship between screen time and obesity or SO.

It is well established that sociodemographic factors are associated with childhood obesity, 2,17,18 and this relationship appears to be particularly strong when it comes to risk for SO. Our results reveal an increased risk of SO among children of racial and ethnic minority status, children of parents with low educational attainment, children of single-parent households, and children of households with income below the FPL. In results consistent with those within existing literature, a lack of breastfeeding was associated increased obesity and, on the basis of our findings, increased odds of SO. ${ }^{19-21}$ Taken together, these findings highlight a level of disparity for this subgroup not previously described. Although the number of children with SO in this sample is not adequately powered for consideration of these multiple factors concurrently, it is important to acknowledge that for each of these sociodemographic variables, a doseresponse association was evident as the severity of obesity increased.
Energy intake and diet quality in children with SO was only modestly different from that of children with NW, and these small differences were not statistically significant. Similar nonsignificant trends with respect to higher energy intake and higher weight status have been reported in children 2 to 8 years. ${ }^{22}$ The lack of a difference in reported energy intake could represent under-reporting, which is a known challenge in selfreported ${ }^{23,24}$ as well as in proxyreported dietary intake by adults on behalf of children with excess weight. $^{25}$ It is also plausible that a diet report of appropriate energy intake and/or quality in a child with SO may represent compliance with a current obesity treatment plan under health care supervision.

These data represent a unique look at young children across different weight categories, with a specific focus on preschool-aged children with SO. An 
important caveat is that even with 14 years of data, the number of children with SO in the sample was small, thus limiting the power to detect small group differences and limiting our ability to consider the simultaneous effect of multiple risk factors for SO. ${ }^{26}$ In addition, because the data are cross-sectional, causality cannot be inferred.

Like the authors of previous studies, we provide evidence that children from families with socioeconomic disadvantage and children who have racial and ethnic minority status are at a higher risk for SO. This disparity reveals the need to develop culturally-sensitive interventions for subgroups. More than any other modifiable behavior studied in this analysis, increased amounts of screen time were associated with increased odds of obesity, particularly SO. This finding adds to recent studies in which authors implicated screen time and sedentary behaviors in weight gain among children. Pediatricians should be encouraged to emphasize limiting screen time in this age group, as recommended by the American Academy of Pediatrics. ${ }^{10,11}$

\section{CONCLUSIONS}

Although SO among preschoolaged children has been previously quantified, this is the first study we are aware of in which the authors attempt to better characterize this high-risk group by contextualizing them in comparison with peers who have NW, OW, or obesity. The findings suggest a possible spectrum of risk, with children with SO having the greatest exposure to markers of socioeconomic disadvantage. Future researchers need to help us better understand the behavioral and physiologic mechanisms and relationships behind the risk factors noted in our study and their impact on long-term morbidity.

\section{ABBREVIATIONS}

CI: confidence interval

FPL: federal poverty level

HBW: high birth weight

HEI-2010: Healthy Eating Index 2010

MEC: mobile examination center

NW: normal weight

OR: odds ratio

OW: overweight

SO: severe obesity

the study, topical expertise in pediatric obesity for preparation of the manuscript, and reviewed and revised the manuscript; and all authors approved the final manuscript as submitted and agree to be accountable for all aspects of the work.

Dol: https://doi.org/10.1542/peds.2017-3228

Accepted for publication Dec 12, 2017

Address correspondence to June M. Tester, MD, MPH, UCSF Benioff Children’s Hospital Oakland, 747 52nd Street, 0akland, CA 94609. E-mail: jtester@chori.org PEDIATRICS (ISSN Numbers: Print, 0031-4005; Online, 1098-4275).

Copyright @ 2018 by the American Academy of Pediatrics

FINANCIAL DISCLOSURE: The authors have indicated they have no financial relationships relevant to this article to disclose.

FUNDING: Secured from the American Academy of Pediatrics Institute for Healthy Childhood Weight and the Children's Hospital Association and by the National Institutes of Health with 1K23HD075852 (Tester),1K99HD84758 (Leung), and K23HD083439 (Phan). Funded by the National Institutes of Health (NIH).

POTENTIAL CONFLICT OF INTEREST: The authors have indicated they have no potential conflicts of interest to disclose.

\section{REFERENCES}

1. Hales CM, Carroll MD, Fryar CD, Ogden CL. Prevalence of obesity among adults and youth: United States, 20152016. NCHS Data Brief. 2017;(288): $1-8$

2. Skinner AC, Skelton JA. Prevalence and trends in obesity and severe obesity among children in the United States, 1999-2012. JAMA Pediatr. 2014;168(6):561-566

3. Groner JA, Joshi M, Bauer JA. Pediatric precursors of adult cardiovascular disease: noninvasive assessment of early vascular changes in children and adolescents. Pediatrics. 2006;118(4):1683-1691
4. Centers for Disease Control and Prevention; National Health and Nutrition Examination Survey. National Health and Nutrition Examination Survey (NHANES): Anthropometry Procedures Manual. Atlanta, GA: Centers for Disease Control and Prevention; 2004

5. National Center for Chronic Disease Prevention and Health Promotion, Centers for Disease Control and Prevention. An SAS program for the CDC growth charts. Available at: www. cdc.gov/nccdphp/dnpao/growthcharts/ resources/sas.htm. Accessed March 26, 2015
6. Kelly AS, Barlow SE, Rao G, et al; American Heart Association Atherosclerosis, Hypertension, and Obesity in the Young Committee of the Council on Cardiovascular Disease in the Young, Council on Nutrition, Physical Activity and Metabolism, and Council on Clinical Cardiology. Severe obesity in children and adolescents identification, associated health risks, and treatment approaches: a scientific statement from the American Heart Association. Circulation. 2013;128(15):1689-1712

7. Flegal KM, Wei R, Ogden CL, Freedman DS, Johnson CL, Curtin LR. 
Characterizing extreme values of body mass index-for-age by using the 2000 Centers for Disease Control and Prevention growth charts. Am J Clin Nutr. 2009;90(5):

1314-1320

8. Johnson CL, Paulose-Ram R, Ogden $\mathrm{CL}$, et al. National health and nutrition examination survey: analytic guidelines, 1999-2010. Vital Health Stat 2. 2013;(161):1-24

9. Fulton JE, Wang $X$, Yore MM, Carlson SA, Galuska DA, Caspersen CJ. Television viewing, computer use, and BMI among U.S. children and adolescents. J Phys Act Health. 2009;6(suppl 1):S28-S35

10. Expert Panel on Integrated Guidelines for Cardiovascular Health and Risk Reduction in Children and Adolescents; National Heart, Lung, and Blood Institute. Expert panel on integrated guidelines for cardiovascular health and risk reduction in children and adolescents: summary report. Pediatrics. 2011;128(suppl 5):S213-S256

11. American Academy of Pediatrics; Committee on Public Education. American Academy of Pediatrics: children, adolescents, and television. Pediatrics. 2001;107(2):423-426

12. Dietary Guidelines Advisory Committee. Report of the Dietary Guidelines Advisory Committee on the Dietary Guidelines for Americans, 2010, to the Secretary of Agriculture and the Secretary of Health and Human Services. Washington, DC: Agricultural Research Service; 2010
13. Hiza HAB, Guenther PM, Rihane Cl. Diet Quality of Children Age 2-17 Years as Measured by the Healthy Eating Index: Nutrition Insight 52. Alexandria, VA: United States Department of Agriculture Center for Nutrition Policy and Promotion; 2013

14. Bowman S, Friday S, Moshfegh A. MyPyramid Equivalents Database 2.0 for USDA Survey Foods, 20032004. Food Surveys Research Group. Beltsville, MD: Beltsville Human Nutrition Research Center, Agricultural Research Service, US Department of Agriculture; 2008

15. Flores G, Lin H. Factors predicting severe childhood obesity in kindergarteners. Int J Obes. 2013:37(1):31-39

16. Anderson SE, Economos CD, Must A. Active play and screen time in US children aged 4 to 11 years in relation to sociodemographic and weight status characteristics: a nationally representative crosssectional analysis. BMC Public Health. 2008;8(1):366

17. Singh GK, Siahpush M, Kogan MD. Rising social inequalities in US childhood obesity, 2003-2007. Ann Epidemiol. 2010;20(1):40-52

18. Singh GK, Kogan MD, Van Dyck PC, Siahpush M. Racial/ethnic, socioeconomic, and behavioral determinants of childhood and adolescent obesity in the United States: analyzing independent and joint associations. Ann Epidemiol. 2008;18(9):682-695

19. Armstrong J, Reilly JJ; Child Health Information Team. Breastfeeding and lowering the risk of childhood obesity. Lancet. 2002;359(9322):2003-2004

20. Harder T, Bergmann R, Kallischnigg G, Plagemann A. Duration of breastfeeding and risk of overweight: a meta-analysis. Am J Epidemiol. 2005;162(5):397-403

21. Hediger ML, Overpeck MD, Kuczmarski RJ, Ruan WJ. Association between infant breastfeeding and overweight in young children. JAMA. 2001;285(19):2453-2460

22. Skinner AC, Steiner MJ, Perrin EM Self-reported energy intake by age in overweight and healthy-weight children in NHANES, 2001-2008. Pediatrics. 2012;130(4). Available at: www.pediatrics.org/cgi/content/full/ 130/4/e936

23. Lichtman SW, Pisarska K, Berman ER, et al. Discrepancy between selfreported and actual caloric intake and exercise in obese subjects. $N$ Engl $J$ Med. 1992;327 (27):1893-1898

24. Bandini LG, Schoeller DA, Cyr HN, Dietz WH. Validity of reported energy intake in obese and nonobese adolescents. Am J Clin Nutr. 1990;52(3): 421-425

25. Börnhorst C, Huybrechts I, Ahrens W, et al; IDEFICS Consortium. Prevalence and determinants of misreporting among European children in proxyreported $24 \mathrm{~h}$ dietary recalls. $B r \mathrm{~J}$ Nutr. 2013;109(7):1257-1265

26. Davison KK, Birch LL. Childhood overweight: a contextual model and recommendations for future research. Obes Rev. 2001;2(3):159-171 